\title{
Exploration on Clothing Plate and Manufacture Integrated Teaching in Colleges and Universities
}

\author{
Fei $\mathrm{Liu}^{1}$, Kai $\mathrm{Li}^{2}$ \\ ${ }^{1}$ Jiangxi Institute of Fashion Technology, Clothing Design Branch, Nanchang, Jiangxi, 330201 \\ 2 Jiangxi Institute of Fashion Technology, Clothing Management Branch, Nanchang, Jiangxi, \\ 330201
}

Keywords: Colleges and Universities, Clothing Plate and Manufacture, Integrated Teaching, Exploration

\begin{abstract}
Clothing plate making clothing and colleges have courses, especially clothing plate this course, it is the focus of major fashion schools teaching courses for students to learn fashion design has a very important role. But in our practice today, teaching the plate and making costumes, there are still some problems, we need to take certain methods to be addressed. Clothing plate making teaching and integration on this basis is one important way to solve, and better able to grasp the integrated teaching students' movements, they can be more conducive for learning fashion design. This article summarizes the current problems appear in Garment Colleges in teaching in the analysis based on the teaching of the plate and made clothing to draw relevant recommendations and provide some suggestions for the future of clothing Teaching.
\end{abstract}

\section{Introduction}

Universities should offer clothing and clothing plate making this course, and this course students' learning plays an important role, but on this basis, teaching methods adopted and major institutions are not the same, even within a college, different teachers will have their own different teaching methods and different teaching philosophy. So they presented the results of different teaching, teaching the results obtained are also different. With the development of society, the ability of talent increasingly high demand, therefore, in the way of teaching have different degrees of innovation. Although the production of clothing plate with two separate courses, but its interior has deep links these relationships we are required, linking the clothing of the teaching process and making the plate, the plate is formed with the integration of teaching the production of clothing mode, which is currently the most clothing colleges a new teaching model of scientific and feasibility of the students will also play a significant role, but this is to be carried out in which to explore and apply the specific method, We need further exploration.

\section{The Meaning and Contact of the Clothing Plate and Manufacture}

Clothing plate is an essential fashion design courses at the college and in clothing is a learning process to go through. Any students who want to learn fashion design, this course must be to master. Clothing plate refers to the full understanding of the clothing will be three-dimensional design of three-dimensional fashion design ideas into a two-dimensional plane of the technology, the focus of this course is to study fashion design, is to bridge ideas into practice, but also in other practical courses on the basis of, and in the existing curriculum teaching, clothing plate is playing a more 
important role. With respect to the plate in terms of clothing, clothing production is based on the effect of the plane up study of clothing production technology, technology, and quality in the production of clothing, content engineering, is the production of a follow-up procedure can be said that the clothing of the plate is the prerequisite and basis for the production of three-dimensional things will only become something transformed two-dimensional plane, it can be manufactured in accordance with its. Clothing plate and making a relationship before and after the order, but in the present teaching, often have been neglected in this relationship, is an issue requiring attention.

\section{The Insufficient Exists in Clothing Plate and Making Teaching}

China is now the fashion design education in teaching there is a way of thinking and not uniform, the major colleges and universities for teaching fashion design has its own set of teaching mode, and different teachers for each faculty has its own different ways in the teaching of each teacher in their own way of teaching, the effect achieved is not the same, it is difficult in the teaching it is difficult to reach a unified model. Secondly, there are still teaching courses defective design problems due to the different institutions have different teaching modes on the courses there will be some differences, on this basis, there will be no courses unified, and some institutions in curriculum design also arranged a very unreasonable, for example, the production of clothing on the front plate of course, they believe in the learning process should first learn the theory of knowledge, learn and then practice, That plane will be produced on the three-dimensional conversion before, although in theory is reasonable, but on the practical operation, the first three-dimensional learning in practice the ideas into practice, and again on the basis of this study up plane theoretical knowledge, so as to more accurately to teach good students, from practice to understand the principles of learning, in order to more effectively improve the learning efficiency.

\section{The Recommendations of Clothing Plate and Make Integrated Teaching}

Play in teaching a very important role in the concept is teaching, teaching philosophy is the focus of teaching, in the teaching process is a guiding significance presence, guiding the teaching process. Therefore, different teaching philosophy guided teaching mode are different, the resulting effect of teaching is different. Now fashion design teaching in the most serious problem is the course sequence is reversed plate to make the relationship between theory and practice there is still a dispute, first learn theory and practice to learn now also become one of the major colleges and universities teaching problem. To the author in a lot of practice in the lessons learned is to guide students to learn practical things, the idea of three-dimensional design into a plane, at this point in the introduction of Print Production theoretical knowledge, this teaching sequence is like learning in the process, starting with a fundamental understanding of the principles of a thing, and then go up on this basis from the perspective of theoretical knowledge discovered the secret, and thus a more systematic study. Change curriculum design, plate-making and production of the order of clothing a good reason, from the foundation up practical understanding of theoretical knowledge, so that students learn to make knowledge more profound.

Another important recommendation is to enrich the classroom in the form of the plate and on the integrated teaching in the manufacture of clothing. First, the clothing plate and making itself a basis for follow-up relationship with them integration teaching thing itself is a very viable, and secondly, the process in this case be integrated in need from another aspect to seize the students' interest, and that is as far as possible in the form of rich classroom on the existing foundation, so that students in a fun atmosphere down to learn more, for example, in the teaching process can be embedded in 
different themes, especially students interested in fashion theme, in the context of these themes, to a greater extent to stimulate student interest, so that when they LESSONS content more profound memories.

A sound education system is an important supporting a good teaching mode, with the perfect teaching system, we will be able to go from side to ensure more students have reliable dependence. For clothing plate making and production is concerned, a good complete teaching system becomes even more important. Especially in the current status of teaching, the major colleges and universities have different teaching concept and mode, an excellent education system has become more important. So now we must pay attention to major colleges and universities and making the clothing plate integration in the first place, this combination is the combination of theory and practice in the true sense, combine the two and make full use of them, we must It can give students a more reliable study results.

\section{Conclusion}

Clothing apparel design and production of plate-making is an important program, the two combined to form a complete system of teaching, theory and practice to fully combine to give students a different experience, especially in the mode of teaching philosophy to not unified, the more should pay attention to this problem in a number of practice on the basis of the conclusions of view, to promote and facilitate the integration of education and production of clothing plate is the best way, is worth in modern teaching methods respected.

\section{REFERENCE:}

[1] Su Junqiang, Tian Tian, Li Hong. knowledge-based Innovative Education fermentation -... And Technology professional clothing plate example [J]. Taiyuan Urban Vocational College of Technology 2010 (11).

[2] Jiangxi Clothing Vocational and Technical College Fashion Design, Footwear Design and Technique Speciality been identified as Jiangxi College Specialty [J]. Textile Education. 2011 (01).

[3] Lu Jian. Horizontal version of the division mechanism of the birth of technical experts of the textile industry, "Lone Star Cup" clothing plate division (computerized flat knitting machine) Skills Contest Final Closing 2015 [J]. Textile and Apparel Weekly. 2015 (29).

[4] Zhang Heng. 3D-LookSailorXt System on the basis of clothing pattern design [J]. Changchun Institute of Technology (Natural Science). 2015 (03).

[5] Wang Xiaoli, Liu Yongmei. typical male shirt design method of comparative experimental analysis [J]. Zhejiang Textile \& Fashion College. 2016 (01). 